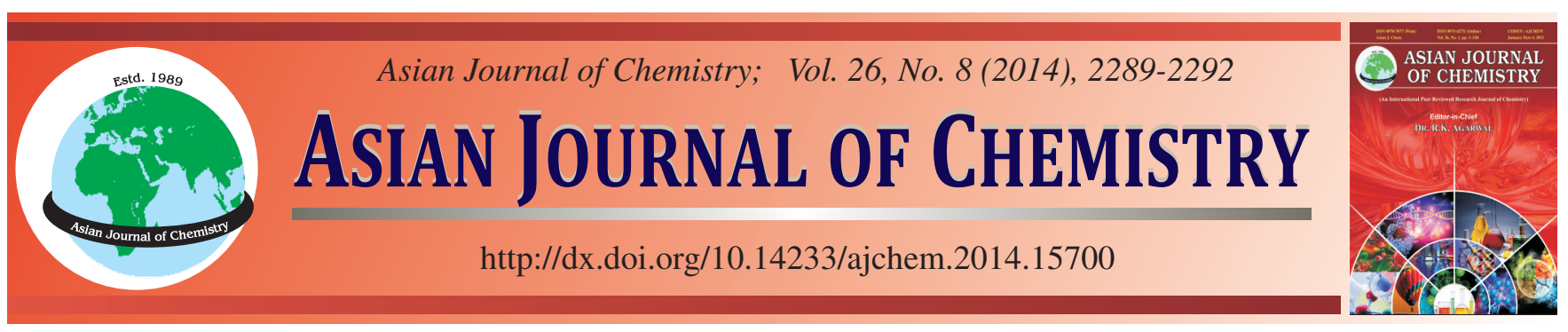

\title{
Extraction of Chlorophyll-a from Eutrophic Water by Repeated Freezing and Thawing-Extraction Method
}

\author{
G.M. Zeng, J. Zhou*, T. HuAng, S.Y. Liu, F.F. Ji and P. Wang
}

Faculty of Urban Construction and Environmental Engineering, Key Laboratory of Three Gorges Reservoir Region's Eco-Environment (Ministry of Education), Chongqing University, Sha Zheng Street, Chongqing 400045, P.R. China

*Corresponding author: E-mail: zhoujiantt@126.com

Received: 29 April 2013;

Accepted: 8 November 2013;

Published online: 15 April 2014;

AJC-15010

\begin{abstract}
This work described the extraction processes of chlorophylls was analyze during two extraction techniques, namely the cool acetone method and acetone repeated freezing and thawing-extraction method as the chlorophyll-a extraction agent, and the results were compared. The objective of this study was to use the uniform design to optimization of the extraction of chlorophyll-a from freshwater green algae by two different methods used acetone. Extracted chlorophyll-a was investigated by fourier transform infrared spectroscopy. These results suggested that there is significant statistical difference between these two methods. The acetone repeated freezing and thawing-extraction method has more advantages than the rubbing-acetone method, which is faster and easier to handle, more complete extraction and lower toxic.
\end{abstract}

Keywords: Chlorophyll a, Rubbing, Uniform design, Repeated freezing and thawing-extraction.

\section{INTRODUCTION}

Accurate quantication of chlorophyll a is an important step in estimating phytoplankton biomass in both marine and freshwater environments. Although the method of detection and quantication of chlorophyll is well established, this process of method are more or less cumbersome operation, human error, and the long contact time with acetone, are not conducive to the health of the operator ${ }^{1-3}$. Therefore, laboratory personnel have made a lot of research on improving the extraction method of chlorophyll.

Presently, most commonly methanol,acetone and ethanol have been used as the solvent ${ }^{4-7}$. Other solvents such as chloroform, dimethyl sulfoxide ${ }^{8-15}$ have been studied. Although researchers have noted that solvents can vary in their ability to extract chlorophyll-a from different eutrophic water ${ }^{16-24}$, for the risk of using a solvent with low extraction efficiency is low accuracy in terms of determining actual chlorophyll-a concentration, so it is important to determine the most effective solvent for a particular set of eutrophic water.

So far, an experiment, which is not only provides more information but also makes it possible to get optimal experimental conditions by a good design and suitable model. Uniform design (UD) which was proposed by Wang and Fang, based on quasi-Monte Carlo method or number-theoretic method. In our experience, the merits of the uniform design method are at least as follows ${ }^{25-28}$ : one is that it is able to produce samples with high representativeness in the studied experimental domain. The other is robustness. Last but not least is multiple levels. It provides the largest possible number of levels for each factor among all experimental designs.

To our best of knowledge, however, there are no studies that formally compare the rubbing method and repeated freezing and thawing-extraction method for chlorophyll-a to the same degree that we have attempted in this study. Therefore, the aim of the present study was to use the uniform design to optimization of the extraction of chlorophyll-a from eutrophic water by two different methods used acetone. Another goal was to establish a simple, rapid, reliable and economical method for chlorophyll-a extraction.

\section{EXPERIMENTAL}

Eutrophic water used in the experiments, which was gathered at lake of Chong Qing university, China, and were stored in a sealed brown glass at $4{ }^{\circ} \mathrm{C}$. All chemicals used were of analytical grade.

Rubbing method: Firstly,the water samples are concentrated. Filtration quantitative volume of water samples and the cellulose acetate membrane of filtration was frozen 6 to $8 \mathrm{~h}$ in refrigerator and then, sample extraction. Put the membrane of freezing in a mortar, adding a small amount of magnesium carbonate powder and $2-3 \mathrm{~mL} 90 \%$ of acetone, thoroughly 
TABLE-1

FACTORS AND LEVELS OF UNIFORM EXPERIMENTAL DESIGN OF RUBBING

\begin{tabular}{lcccccc}
\hline \multicolumn{1}{c}{ Factors } & \multicolumn{5}{c}{ Levels } \\
\cline { 2 - 7 } \multicolumn{1}{c}{} & 1 & 2 & 3 & 4 & 5 & 6 \\
\hline X1 Sample volume (mL) & 50 & 100 & 150 & 200 & 250 & 300 \\
X2 Acetone concentration (\%) & 50 & 60 & 70 & 80 & 90 & 100 \\
X3 Extraction time (h) & 4 & 5 & 6 & 7 & 8 & 9 \\
X4 Centrifugation time (min) & 5 & 10 & 15 & 20 & 25 & 30 \\
\hline
\end{tabular}

TABLE-2

FACTORS AND LEVELS OF UNIFORM EXPERIMENTAL DESIGN OF REPEATED FREEZING AND THAWING-EXTRACTION

\begin{tabular}{lcccccc}
\hline \multicolumn{1}{c}{ Factors } & \multicolumn{5}{c}{ Levels } \\
\cline { 2 - 6 } \multicolumn{1}{c}{} & 1 & 2 & 3 & 4 & 5 & 6 \\
\hline X1 Sample volume (mL) & 50 & 100 & 150 & 200 & 250 & 300 \\
X2 Acetone concentration (\%) & 50 & 60 & 70 & 80 & 90 & 100 \\
X3 Freezing and thawing times & 1 & 2 & 3 & 4 & 5 & 6 \\
X4 Extraction time (h) & 5 & 10 & 15 & 20 & 25 & 30 \\
\hline
\end{tabular}

grinding and extraction of chlorophyll a. After that, centrifugal for $20 \mathrm{~min}$ at $4000 \mathrm{rpm}$. The supernatant was transferred to $10 \mathrm{~mL}$ colorimetric tubes, and with $90 \%$ acetone fixed volume to $10 \mathrm{~mL}$, shake it. Finally, the supernatant spectrophotometer cuvette with a $1 \mathrm{~cm}$ optical path, read 750, 663, 645 and $630 \mathrm{~nm}$ wavelength absorbance degrees, respectively, and the blank was $90 \%$ acetone, chlorophyll a content was calculated as follows:

$$
\text { Chlorophyll-a }\left(\mathrm{mg} / \mathrm{m}^{3}\right)=\left[11.64 \times\left(\mathrm{D}_{663}-\mathrm{D}_{750}\right)-2.16 \times\right.
$$$$
\left.\left(\mathrm{D}_{645}-\mathrm{D}_{750}\right)+0.10 \times\left(\mathrm{D}_{630}-\mathrm{D}_{750}\right)\right] \mathrm{V}_{1} / \mathrm{V} / \delta
$$

$\mathrm{V}$ is a water sample volume $(\mathrm{L}), \mathrm{D}$ is the absorbance, $\mathrm{V}_{1}$ extract given volume $(\mathrm{mL}), \delta$ cuvette Cheng $(\mathrm{cm})$.

Repeated freezing and thawing-extraction: In the first, filtration quantitative volume of water samples and the cellulose acetate membrane of filtration was placed at $-20{ }^{\circ} \mathrm{C}$ and room temperature under repeated freezing and thawing of 3 to 5 times, the freezing time is about $20 \mathrm{~min}$, the defrosting time is about $5 \mathrm{~min}$. In addition, the membrane after repeated freezing and thawing placed filled with $10 \mathrm{~mL}$ of acetone (90\%) of the centrifuge tube, shaken for $1 \mathrm{~min}$ until the membrane was completely dissolved under the conditions of dark. Put the centrifuge tube at $4{ }^{\circ} \mathrm{C}$ at $5 \mathrm{~h}$ extraction, the extraction process required to shaking for 1 or 2 times. Lastly, centrifuged for $15 \mathrm{~min}$ at $4000 \mathrm{r} / \mathrm{min}$ and determinate the absorbance of the supernatant of the centrifuge tube at a wavelength of 630 , 645,663 and $750 \mathrm{~nm}$. The content of chlorophyll-a was calculated the same as mentioned in rubbing method.

Experimental design: Uniform design (UD) is a collection of mathematical and statistical techniques, is usually used for modeling and analyzing problems in which a response of interest is affected by several variables and the aim is to optimize the response. The extraction of chlorophyll-a was treated as the response influenced by many potential variables. Six factors, including filtrate volume, freezing and thawingextraction times, centrifugation speed, acetone concentration, extraction time and extraction temperature were studied. It was found that the four of them (filtrate volume, acetone concentration, extraction time and extraction temperature) and the other four of them (filtrate volume, freezing times, acetone concentration and extraction time) made greater contribution to extraction of chlorophyll-a by rubbing and repeated freezing and thawing-extraction, respectively. Several levels of these four factors are shown in Tables 1 and 2. The uniform design design consisted of 12 experiments (Tables 3 and 4). Both linear and quadratic effects of the four variables were calculated, as well as their possible interactions, on chlorophyll-a. Their significance was evaluated by DPS software. A quadratic polynomial equation was proposed to describe the mathematical relationship between the response and the variables. The fit of the model was evaluated by the determination of $\mathrm{R}$ and adjusted Ra coeffcient.The validation of the model optimum value of selected variables was obtained by solving the regression equation. The predicted optimum value was confirmed by the experiment using the selected optimum values of the four variables.

Analytical methods: Fourier transform infrared (FTIR) spectra were recorded in 4000-400 $\mathrm{cm}^{-1}$ region using a Spectrum GX (Perkin Elmer, US). Discs were prepared by mixing $1 \mathrm{~mL}$ sample with $\mathrm{GaF}$. The background spectrum of pure potassium bromide was subtracted from that of the sample spectrum.

\section{RESULTS AND DISCUSSION}

Uniform design is based on uniform distribution in number theory. It makes experiment points uniformly scattered in the range of experiment parameters for getting more information by less experiments. Uniform design for optimization of chlorophyll-a extraction by rubbing and repeated freezing and thawing-extraction.

TABLE-3

EXPERIMENTAL DESIGN OF SAMPLE VOLUME (X1), ACETONE CONCENTRATION (X2), EXTRACTION TIME (X3), AND CENTRIFUGATION TIME (X4), AND THE RESULTS FOR CHLOROPHYLL A BY RUBBING

\begin{tabular}{cccccc}
\hline Runs & X1 & X2 & X3 & X4 & $\begin{array}{c}\text { Chlorophyll-a } \\
\left(\mathrm{Mg} / \mathrm{m}^{3}\right)\end{array}$ \\
\hline N1 & 4 & 1 & 3 & 1 & 10.77 \\
N2 & 3 & 6 & 4 & 1 & 24.11 \\
N3 & 1 & 4 & 1 & 2 & 43.29 \\
N4 & 5 & 2 & 1 & 4 & 9.77 \\
N5 & 2 & 3 & 2 & 6 & 7.29 \\
N6 & 2 & 2 & 6 & 3 & 12.08 \\
N7 & 3 & 1 & 4 & 5 & 6.90 \\
N8 & 5 & 4 & 6 & 6 & 14.12 \\
N9 & 6 & 5 & 2 & 3 & 9.84 \\
N10 & 1 & 5 & 5 & 4 & 26.96 \\
N11 & 4 & 6 & 3 & 5 & 15.10 \\
N12 & 6 & 3 & 5 & 2 & 9.29 \\
\hline
\end{tabular}




\begin{tabular}{|c|c|c|c|c|c|}
\hline \multicolumn{6}{|c|}{$\begin{array}{c}\text { TABLE-4 } \\
\text { EXPERIMENTAL DESIGN OF SAMPLE VOLUME (X1), } \\
\text { ACETONE CONCENTRATION (X2), FREEZING AND } \\
\text { THAWING-EXTRACTION TIMES (X3), AND EXTRACTION } \\
\text { TIME (X4), AND THE RESULTS FOR CHLOROPHYLL-A BY } \\
\text { REPEATED FREEZING AND THAWING-EXTRACTION }\end{array}$} \\
\hline Runs & $\mathrm{X} 1$ & $\mathrm{X} 2$ & X3 & $\mathrm{X} 4$ & $\begin{array}{c}\text { Chlorophyll-a } \\
\left(\mathrm{mg} / \mathrm{m}^{3}\right)\end{array}$ \\
\hline N1 & 4 & 1 & 3 & 1 & 3.22 \\
\hline $\mathrm{N} 2$ & 3 & 6 & 4 & 1 & 16.53 \\
\hline N3 & 1 & 4 & 1 & 2 & 12.09 \\
\hline N4 & 5 & 2 & 1 & 4 & 3.82 \\
\hline N5 & 2 & 3 & 2 & 6 & 16.64 \\
\hline N6 & 2 & 2 & 6 & 3 & 50.43 \\
\hline N7 & 3 & 1 & 4 & 5 & 15.58 \\
\hline N8 & 5 & 4 & 6 & 6 & 16.09 \\
\hline N9 & 6 & 5 & 2 & 3 & 6.14 \\
\hline N10 & 1 & 5 & 5 & 4 & 15.50 \\
\hline N11 & 4 & 6 & 3 & 5 & 16.93 \\
\hline N12 & 6 & 3 & 5 & 2 & 13.24 \\
\hline
\end{tabular}

Quadratic polynomial stepwise regression analysis with the the DPS software data processing system on the experimental results in Tables 3 and 4, and the model was significant inspection, the regression equation:

$$
\begin{gathered}
\mathrm{Y}=28.88804351+8.118626944 \mathrm{X} 2-11.512671305 \mathrm{X} 3- \\
0.25102744285 \mathrm{X} 1 * \mathrm{X} 1+0.5217645706 \mathrm{X} 3 * \mathrm{X} 3- \\
0.9178439931 \mathrm{X} 4 * \mathrm{X} 4-1.1705172886 \mathrm{X} 1 * \mathrm{X} 2+ \\
0.8379488724 \mathrm{X} 1 * \mathrm{X} 3-0.26710413569 \mathrm{X} 2 * \mathrm{X} 3- \\
0.12965477078 \mathrm{X} 2 * \mathrm{X} 4+1.39 \\
\mathrm{Y}=43.1965267+12.421637228 \mathrm{X} 1+ \\
\mathrm{Y}=43.1965267+12.421637228 \mathrm{X} 1+11.123689355 \mathrm{X} 2+ \\
6.337015550 \mathrm{X} 4-1.6993336297 \mathrm{X} 1 * \mathrm{X} 1+ \\
2.7970920889 \mathrm{X} 3 * \mathrm{X} 3-0.3228545733 \mathrm{X} 1 * \mathrm{X} 3- \\
0.5169343496 \mathrm{X} 1 * \mathrm{X} 4-2.8886101906 \mathrm{X} 2 * \mathrm{X} 3+ \\
0.03526552168 \mathrm{X} 2 * \mathrm{X} 4-1.3861330496 \mathrm{X} 3 * \mathrm{X} 4
\end{gathered}
$$

The rubbing of multiple correlation coefficient of the equation $\mathrm{Ra}=0.9997, \mathrm{~F}=2058.2338, \mathrm{p}=0.0172, \mathrm{~S}=0.2472$, and the repeated freezing and thawing-extraction of multiple correlation coefficient of the equation $\mathrm{Ra}=1.0000, \mathrm{~F}=$ 42710.6967, $\mathrm{p}=0.0038, \mathrm{~S}=0.0615$. These equations can be well fitting Rubbing and Repeated freezing and thawingextraction of chlorophyll-a. Tables 5 and 6 variables significantly test p-value size, we can see the impact of the chlorophyll-a content of various factors on the rubbing and repeated freezing and thawing-extraction of size are $\mathrm{X} 4 \mathrm{X} 4=\mathrm{X} 3 \mathrm{X} 4>$ $\mathrm{X} 1 \mathrm{X} 3>\mathrm{X} 3>\mathrm{X} 1 \mathrm{X} 2>\mathrm{X} 2>\mathrm{X} 3 \mathrm{X} 3>\mathrm{X} 1 \mathrm{X} 1>\mathrm{X} 2 \mathrm{X} 3>\mathrm{X} 2 \mathrm{X} 4$ and $\mathrm{X} 1=\mathrm{X} 2=\mathrm{X} 4=\mathrm{X} 1 \mathrm{X} 1=\mathrm{X} 3 \mathrm{X} 3=\mathrm{X} 2 \mathrm{X} 3=\mathrm{X} 3 \mathrm{X} 4>\mathrm{X} 1 \mathrm{X} 3$ $>\mathrm{X} 1 \mathrm{X} 4>\mathrm{X} 2 \mathrm{X} 4$, respectively. It was showed that there were an interaction between the factors. By these experiments to get the best rubbing and repeated freezing and thawing-extraction conditions were: sample volume(X1) $50 \mathrm{~mL}$, acetone concentration (X2) $100 \%$, extraction time $4 \mathrm{~h}$ (X3) and centrifugation time $5 \mathrm{~min}$ (X4), and sample volume (X1) $150 \mathrm{~mL}$, acetone concentration (X2) $50 \%$, repeated freezing and thawingextraction times $6(\mathrm{X} 3)$ and extraction time $5 \mathrm{~h}(\mathrm{X} 4)$, respectively.

Experimental validation of the optimized condition: In order to confirm the optimization results, three experiments in test tubes were performed under the predicted optimal conditions. The mean chlorophyll-a were 58.27 and $63.96 \mathrm{mg} / \mathrm{m}^{3}$,
TABLE-5

RESULTS OF EXPERIMENTAL DATA PROCESSED WITH QUADRATIC POLYNOMIAL REGRESSION FOR RUBBING

\begin{tabular}{ccc}
\hline Partial correlation coefficient & $\mathrm{t}$ & $\mathrm{p}$ \\
\hline $\mathrm{r}(\mathrm{y}, \mathrm{X} 2)=0.9992$ & 24.2732 & 0.0017 \\
$\mathrm{r}(\mathrm{y}, \mathrm{X} 3)=-0.9996$ & 34.9875 & 0.0008 \\
$\mathrm{r}\left(\mathrm{y}, \mathrm{X} 1^{*} \mathrm{X} 1\right)=-0.9939$ & 8.9810 & 0.0122 \\
$\mathrm{r}\left(\mathrm{y}, \mathrm{X} 3^{*} \mathrm{X} 3\right)=0.9977$ & 14.8783 & 0.0045 \\
$\mathrm{r}\left(\mathrm{y}, \mathrm{X} 4^{*} \mathrm{X} 4\right)=-0.9998$ & 45.4073 & 0.0005 \\
$\mathrm{r}\left(\mathrm{y}, \mathrm{X} 1^{*} \mathrm{X} 2\right)=-0.9993$ & 26.3390 & 0.0014 \\
$\mathrm{r}\left(\mathrm{y}, \mathrm{X} 1^{*} \mathrm{X} 3\right)=0.9996$ & 36.7301 & 0.0007 \\
$\mathrm{r}\left(\mathrm{y}, \mathrm{X} 2^{*} \mathrm{X} 3\right)=-0.9817$ & 5.1551 & 0.0356 \\
$\mathrm{r}\left(\mathrm{y}, \mathrm{X} 2^{*} \mathrm{X} 4\right)=-0.9814$ & 5.1116 & 0.0362 \\
$\mathrm{r}\left(\mathrm{y}, \mathrm{X} 3^{*} \mathrm{X} 4\right)=0.9997$ & 43.3032 & 0.0005 \\
$\mathrm{R}=1.0000$ & & \\
$\mathrm{~F}=2058.2338$ & & \\
$\mathrm{P}=0.0172$ & & \\
$\mathrm{~S}=0.2472$ & & \\
$\mathrm{Ra}=0.9997$ & & \\
\hline
\end{tabular}

TABLE-6

RESULTS OF EXPERIMENTAL DATA PROCESSED WITH QUADRATIC POLYNOMIAL REGRESSION FOR REPEATED FREEZING AND THAWING-EXTRACTION

\begin{tabular}{ccc}
\hline Partial correlation coefficient & $\mathrm{t}$ & $\mathrm{p}$ \\
\hline $\mathrm{r}(\mathrm{y}, \mathrm{X} 1)=1.0000$ & 139.5556 & 0.0001 \\
$\mathrm{r}(\mathrm{y}, \mathrm{X} 2)=1.0000$ & 244.7401 & 0.0001 \\
$\mathrm{r}(\mathrm{y}, \mathrm{X} 4)=1.0000$ & 162.3360 & 0.0001 \\
$\mathrm{r}\left(\mathrm{y}, \mathrm{X} 1^{*} \mathrm{X} 1\right)=-1.0000$ & 198.3008 & 0.0001 \\
$\mathrm{r}(\mathrm{y}, \mathrm{X} 3 * \mathrm{X} 3)=1.0000$ & 500.3625 & 0.0001 \\
$\mathrm{r}\left(\mathrm{y}, \mathrm{X} 1^{*} \mathrm{X} 3\right)=-0.9998$ & 54.6560 & 0.0003 \\
$\mathrm{r}\left(\mathrm{y}, \mathrm{X} 1^{*} \mathrm{X} 4\right)=-0.9998$ & 45.5641 & 0.0005 \\
$\mathrm{r}\left(\mathrm{y}, \mathrm{X} 2^{*} \mathrm{X} 3\right)=-1.0000$ & 296.9472 & 0.0001 \\
$\mathrm{r}(\mathrm{y}, \mathrm{X} 2 * \mathrm{X} 4)=0.9845$ & 5.6207 & 0.0302 \\
$\mathrm{r}(\mathrm{y}, \mathrm{X} 3 * \mathrm{X} 4)=-1.0000$ & 131.8986 & 0.0001 \\
$\mathrm{R}=1.0000$ & & \\
$\mathrm{~F}=42710.6967$ & & \\
$\mathrm{P}=0.0038$ & & \\
$\mathrm{~S}=0.0615$ & & \\
$\mathrm{Ra}=1.0000$ & & \\
\hline
\end{tabular}

respectively. It indicated that the repeated freezing and thawing-extraction of chlorophyll a content was 1.10 times as compared with the chlorophyll a by conventional rubbing method.

FTIR spectroscopy: FTIR spectroscopy is an analytical that has been used to identify polysaccharides, check their purity, determine structure and investigate complex and intermolecular interactions. Figs. 1 and 2 showed all the extraction of chlorophyll-a by rubbing and repeated freezing and thawingextraction.

It can be seen that all the spectra are typical style of chlorophyll-a. The absorption at $3449 \mathrm{~cm}^{-1}$ are attributed to chlorophyll-a-OH stretching of adsorbed water of molecules. The C-H stretching occurs at $2970 \mathrm{~cm}^{-1}$ and $2970 \mathrm{~cm}^{-1}$, respectively. The most important bands that helped to identify the phytoplankton plant alcohol component at 2907. 1739 and $1734 \mathrm{~cm}^{-1}$ corresponding to the chlorophyll-a molecular $\mathrm{C}_{7}$ and $\mathrm{C}_{10} \mathrm{C}=\mathrm{O}$ stretching vibration peak, and $1703 \mathrm{~cm}^{-1}$ attributed to the chlorophyll-a molecule $\mathrm{C}_{9} \mathrm{C}=\mathrm{O}$ stretching vibration. Near $1640 \mathrm{~cm}^{-1}$ corresponding chlorophyll-a molecule $\mathrm{C}=\mathrm{C}$ stretching vibration. $1435 \mathrm{~cm}^{-1}$ and $1428 \mathrm{~cm}^{-1}$ chlorophyll-a molecular skeleton vibration. Near $1050 \mathrm{~cm}^{-1}$ chlorophyll-a molecular $\mathrm{C}-\mathrm{H}$ Bending vibration. In comparison to rubbing, repeated 


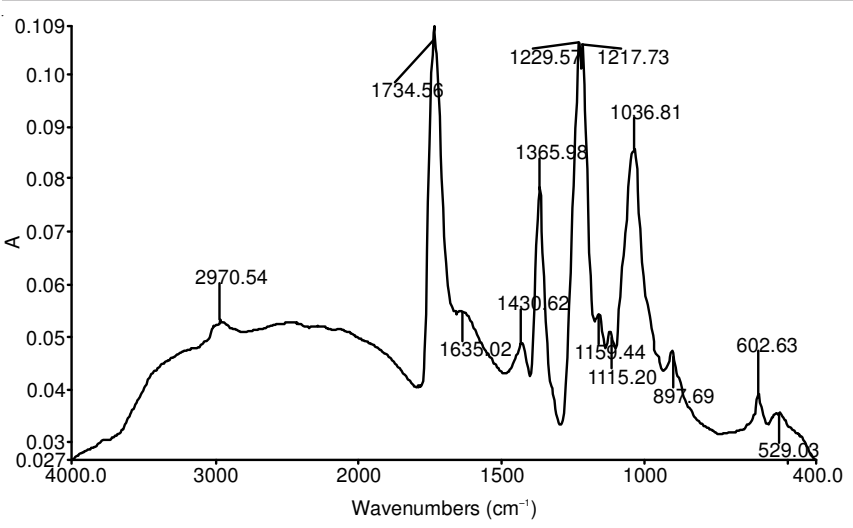

Fig. 1. FTIR spectra of the chlorophyll a by conventional rubbing method

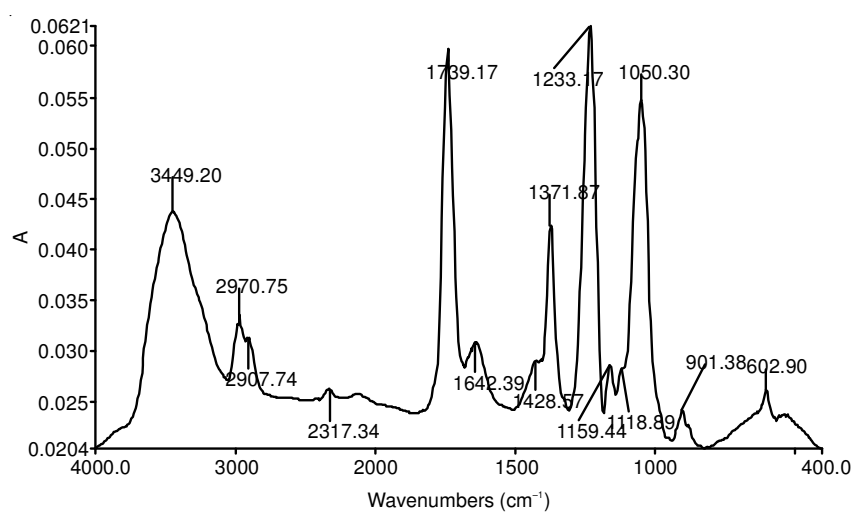

Fig. 2. FTIR spectra of the chlorophyll a by repeated freezing and thawingextraction

freezing and thawing-extraction extracted more chlorophylla content. Experimental studies indicated that pheophytin is very sharp, high strength skeleton vibration peak in the infrared frequency of $1739,1371,1233 \mathrm{~cm}^{-1}$ at all and after repeated freezing and thawing-extraction, the intensity of peak at 1050 $\mathrm{cm}^{-1}$ shifted. It revealed that the bonding of chlorophyll-a breakage at some degree, which suggested the content of chlorophylla is extracted more.

\section{Conclusion}

Repeated freezing and thawing-extraction method compared with the rubbing method, indicated that rubbing method steps were cumbersome, small stability and dangerous to the laboratory personnel. Throughout the process of repeated freezing and thawing-extraction method, the extract was always maintained in a closed cuvette, enhanced the extraction of chlorophyll-a release from cells, with less human error and easy operation, which was suitable for the routine water quality monitoring. A number of experiments noted that repeated freezing and thawing-extraction method for the determination of chlorophyll-a in eutrophic water method has simple, fast, low toxicity and high extraction efficiency advantages, under the optimal conditions: sample volume (X1) $150 \mathrm{~mL}$, acetone concentration (X2) $50 \%$, repeated freezing and thawingextraction times $6(\mathrm{X} 3)$ and extraction time $5 \mathrm{~h}(\mathrm{X} 4)$.

\section{ACKNOWLEDGEMENTS}

This work was supported by grant from the Major National Water Pollution Control and Management of Project of Science and Technology (2012ZX07307-002, 0219002305004/003) and Postgraduate Science and Technology Innovation Fund of Chongqing University, China (CDJXS12211102).

\section{REFERENCES}

1. G. Dall'Olmo and A.A. Gitelson, Appl. Opt., 44, 412 (2005).

2. A. Gilerson, A. Gitelson, J. Zhou, D. Gurlin, W. Moses, I. Ioannou and S.A. Ahmed, Opt. Express, 18, 24109 (2010).

3. A. Gitelson, D. Gurlin, W. Moses and T. Barrow, Environ. Res. Lett., 4, 045003 (2009).

4. D. Gurlin, A.A. Gitelson and W.J. Moses, Remote Sens. Environ., 115, 3479 (2011).

5. C. Le, Y. Li, Y. Zha, D. Sun, C. Huang and H. Lu, Remote Sens. Environ., 113, 1175 (2009).

6. W. Moses, A. Gitelson, S. Berdnikov and V. Povazhnyy, IEEE Geosci. Remote Sens. Lett., 6, 845 (2009b).

7. Y.Z. Yacobi, W.J. Moses, S. Kaganovsky, B. Sulimani, B.C. Leavitt and A.A. Gitelson, Water Res., 45, 2428 (2011).

8. L. Chen, Z. Xie, C. Hu, D. Li, G. Wang and Y. Liu, J. Arid Environ., 67, 521 (2006).

9. Z.M. Xie, Y.D. Liu, C.X. Hu, L.Z. Chen and D.H. Li, Soil Biol. Biochem., 39, 567 (2007).

10. W.B. Wang, C.Y. Yang, D.S. Tang, D.H. Li, Y.D. Liu and C.X. Hu, Sci. China C Life Sci., 50, 530 (2007).

11. B. Büdel, T. Darienko, K. Deutschewitz, S. Dojani, T. Friedl, K.I. Mohr, M. Salisch, W. Reisser and B. Weber, Microb. Ecol., 57, 229 (2009).

12. W. Yang, B. Matsushita, J. Chen, T. Fukushima and R. Ma, IEEE Geosci. Remote Sens. Lett., 7, 655 (2010).

13. H. Schiller and R. Doerffer, IEEE Trans. Geosci. Rem. Sens., 43, 1585 (2005).

14. S.G.H. Simis, S.W.M. Peters and H.J. Gons, Limnol. Oceanogr., 50, 237 (2005).

15. S.G.H. Simis, A. Ruiz-Verdu, J.A. Dominguez-Gomez, R. PenaMartinez, S.W.M. Peters and H.J. Gons, Remote Sens. Environ., 106, 414 (2007).

16. D. Suggett, C. Moore, A. Hickman and R.J. Geider, Mar. Ecol. Prog. Ser., 376, 1 (2009).

17. J. Zhao, W. Cao, Y. Yang, G. Wang, W. Zhou and Z. Sun, Mar. Pollut. Bull., 56, 1795 (2008).

18. P.V. Zimba and A. Gitelson, Aquaculture, 256, 272 (2006).

19. O. Anneville, J.C. Molinero, S. Souissi, G. Balvay and D. Gerdeaux, J. Plankton Res., 29(S1), i49 (2006).

20. B. Nas, H. Karabork, S. Ekercin and A. Berktay, Environ. Monit. Assess., 157, 375 (2009).

21. M. Bresciani, C. Giardino, D. Longhi, M. Pinardi, M. Bartoli and M. Vascellari, Ital. J. Remote Sens., 41, 147 (2009).

22. R.M. Cavalli, G. Laneve, L. Fusilli, S. Pignatti and F. Santini, J. Environ. Manage., 90, 2199 (2009).

23. C. Giardino, M. Pepe, P.A. Brivio, P. Ghezzi and E. Zilioli, Sci. Total Environ., 268, 19 (2001).

24. G. Wolfram, C. Argillier, J. Bortoli, F. Buzzi, A. Dalmiglio, M.T. Dokulil, E. Hoehn, A. Marchetto, P.-J. Martinez, G. Morabito, M. Reichmann, Š. Remec-Rekar, U. Riedmüller, C. Rioury, J. Schaumburg, L. Schulz and G. Urbanic, Hydrobiologia, 633, 45 (2009).

25. Y.L. Grize, Chemom., 9, 239 (1995).

26. K.T. Fang, Acta Math. Appl. Sin. •., 3, 363 (1980).

27. D.H. Doehlert, Appl. Stat., 19, 231 (1970).

28. X. Chen, X.Q. Ning, B.B. Zhang, Y.L. Wang, G.M. Zeng and C.B. Hu, Asian J. Chem., 24, 1015 (2012). 